\title{
Study of the Policies for the Integrated Development of Urban and Rural Sports Public Services
}

\author{
Wei SHAO ${ }^{1, a,}$, Chao LIU ${ }^{1, b^{*}}$ \\ ${ }^{1}$ School of Physical Education, Huaibei Normal University. Huaibei, 235000, Anhui China \\ ashowv@sina.cn, 'llch@chnu.edu.cn \\ ${ }^{*}$ Corresponding author
}

Keywords: reform and opening, sports public service, integrated development of urban and rural sports, policy and system.

\begin{abstract}
Since the introduction of reforming and opening in China, the policies for the development of urban and rural sports public service can be divided into three phases, i.e. prior development of urban sports, development of urban and rural sports and coordinated development of urban and rural sports. Based on the analysis of policies for the sports public service in different phases, this article explores the manifestations of the policies for the integrated development of urban and rural sports public service. Finally, some countermeasures are proposed for the integrated development of urban and rural sports public service.
\end{abstract}

\section{Introduction}

Since the reforming and opening-up in China, a series of policies and systems have been issued for the development of sports. The release and implementation the policies provide a guiding line and lay a solid foundation for the sports public service in China. However, there has been little systematic research nor rational scrutiny about the policies for the integrated development of urban and rural sports public service.

Evolutionary process of policies and systems for urban and rural sports public service since reform and opening-up

Policies and systems for urban and rural sports public service in $1980 \mathrm{~s}$ - stressing competitive sports and giving priority to the development of urban sports

Since the reform and opening-up, China needs to establish its image on the international stage and show its national strength. Therefore, the competitive sports were emphasized, wishing to achieve excellent performance in the international sports events. This strong political color was well reflected in Notice of Report about the Questions Raised by the Directors of the Provinces, Autonomous Regions and Municipalities under the Central Government Endorsed in April 1981 by the State Council to the State Sports Committee. During this period, the priority was given to the development of urban sports, and this was clearly shown in Notice of Report about the Questions Raised by the Directors of the Provinces, Autonomous Regions and Municipalities under the Central Government, and Notice of Further Improvement of Sports released by the Central Committee in 1984, respectively. The coordinated growth of urban and rural sports is not stressed in the policies and systems, and hinders the rural sports development in the following years.

\section{Policies and systems for urban and rural sports public service in 1990s - balanced development of urban and rural sports}

After 1990s, the national physical fitness is receiving more and more attention and a series of policies have been released, such as Outlines of the National Fitness Program and Sports Law of the People's Republic of China. It can be clearly seen that both urban and rural sports are emphasized in the outlines 
and sports law. Therefore, there is a transfer from giving priority to the urban sports development to balanced development of both urban and rural sports. This is especially so after the Opinions about Strengthening and Deepening the Sports Development in the Rural Areas was issued in 1996. Since then, the rural sports have been the focus of the sports at the country level. The transfer in policies also indicates that the policies for the coordinated development of urban and rural sports are going to be issued.

\section{Policies and systems for urban and rural sports public service since 2000 - coordinated development of urban and rural sports}

Entering the new century, a series of policies and systems have been issued, such as Opinions of Further Strengthening and Improving Sports Work in the New Period by the State Council, Nationwide Fitness Regulations, Nationwide Fitness Planning ( 2011- 2015 ), etc. Coordinated development of urban and rural sports public service is clearly stated in the policies in the new period. The words like "mutual development", "coordinated development", "balanced development" and "integration of urban and rural areas" often appear in the policies released by all levels of governments. It is clear that mass sports are receiving more and more attention, and this is especially so after Beijing Olympics when China's competitive sports reached its peak. At the same time, under the background of building the harmonious society and the socialist new village, the policy for the development of the rural sports has been changed. This strategic change in the policies for the development of rural sports public service of the country offers a clear direction for the development of the country's sports public service, and provides guidelines for issuing policies for the development of sports public service.

\section{Manifestations of the integration of policies for urban and rural sports public service}

From the perspective of politics, a whole policy involves the issue of, implementation, monitoring and evaluation of a policy. These are the three factors that guarantee expected effect of a policy. It is true in the case of a policy for the integrated development of urban and rural sports public service.

\section{Integration in issuing policies for urban and rural sports public service}

Issuing a policy is a basis for the integrated development of urban and rural sports public service. In order to achieve the integrated development, the reality of the development of urban and rural sports public services should be taken into consideration. This is to say, it is important to make unified plans with due consideration for both urban and rural areas. Based on the review of the sports policies in China, it is obvious that the policies in 1980s gave priority to the development of sports in the urban areas and ignored the development of sports in the rural areas. Now the coordination and integration of both urban and rural sports public services are equally mentioned in the policies. Therefore, it is urgent that all levels of governments should keep up with the times and release corresponding policies, laws and regulations.

\section{Integration in implementing policies for urban and rural sports public services}

The implementation of policies is a crucial factor for the integrated development of urban and rural sports public services. Because of the influence of urban-rural dual structure, sports public service policies could not play its due role in the rural sports. Even now, some of the policies cannot be implemented effectively. At present, the implementing agencies for the policies of urban and rural sports development are the State Administration of Sports, the Mass Sports Department, the Mass Sports Department of Provincial Sports Bureau, the Mass Sports Department of Regional Sports Department and the Mass Sports Department of County Sports Bureau. These governmental departments provide professional guidance for all levels' sports associations and together implement the policies for the development of urban and rural sports. 


\section{Integration in monitoring and evaluating policies for urban and rural sports public services}

Monitoring and evaluation guarantee the integration of urban and rural sports public services. The evaluation of the policy implementation has not been received due attention in China. The governmental agencies are keen to formulate and propaganda policies while often ignore the effectiveness of the policies, which encourages objectively the arbitrary decision-making and brings adverse consequences to economy and society. At present, the monitoring of the government departments is limited only to cities' sports departments at all levels, and as a result, the country's policies become mere formality in the rural areas. Therefore, the monitoring and evaluating should be reinforced and the evaluation index system should be formulated.

\section{Countermeasures for the integration of policies for urban and rural sports public services}

\section{Strengthen personnel training and ensure the implementation of the policy system}

Each policy of the country needs staff to implement, so it is important to strengthen personnel training. In order to achieve the integration of policies for urban and rural sports public services, it is necessary to propaganda the policies for the development of urban and rural sports formulated by the state and the provincial governments, and raise their awareness of the importance of the policies. Secondly, the relevant personnel should know about the policies available to ensure the implementation of the policies. Thirdly, special column should be set to publicize and share the released policies.

\section{Leading role of leaders should bring into play and masses' participation should be improved}

Leading role of the leaders is a crucial factor in implementing the policies for the urban and rural sports public services. Firstly, leaders of all levels should take the lead and set an example for others in order to stop completely all kinds of behaviors and ensure the injustice and authority of the policies and systems. Secondly, the implementation of the policies should become an index for the evaluation of the staff involved. The realization of the goal not only requires strict evaluation and leaders' due attention, but also the masses' participation. However, the reality is that the participation of the public, let alone the farmers, is far from enough. Therefore, the public should be encouraged to participate in the formulation and implementation of the policies for the urban and rural sports public services. A platform should be set up for the masses to express their demands, and the leaders should be ready to accept the masses' supervision. Only by doing so, can the implementation of the policies be more transparent and beneficial for the integrated development of the urban and rural sports public services.

\section{Rural areas should receive more attention in the formulation and implementation of the policies}

At present, the rural area is always in an inferior position. The evolutionary process of the policies for the development of the urban and rural sports public services show that, because prior attention was given to the development of urban sports public service, there exists a gap between the rural and urban sports public services. This has greatly affected the entire promotion of our country's sports undertakings. The county sports bureau is a basic managing department and it plays a very important role not only in publicizing and implementing the nation's policies, but also in formulating and implementing the local policies for the integrated development of urban and rural sports public services. Therefore, all county governments should formulate the policies and systems according to its own characteristic. Meanwhile, monitoring and evaluating systems should be made to ensure the implementation and popular support of the nation's policies.

\section{Making laws for the integrated development of urban and rural sports public services}

A domestic research of the equilibrium of basic public services show that the supply of the basic public services in China is far from enough, and this unbalanced distribution attributes to the unreliable and unstable policy formulation. Based on this analysis, it is advisable that the legislation system for the balanced distribution should be quickened, and the law for the equilibrium of basic public services should be formulated. Accordingly, all the provinces and regions should study and lay down the 
regulations for the integrated development of the urban and rural sports public services in order to ensure the healthy development and fair distribution among urban and rural residents.

\section{Establishing evaluation mechanism for the integrated development of urban and rural sports public services}

So far, there has no evaluation index system for the integrated development of urban and rural sports public services, and as a result, the government cannot effectively assess the development of the urban and rural sports public services. Therefore, local governments should formulate a practical, reasonable evaluation index system, evaluate regularly to ensure the realization of the goals for the integrated development of urban and rural sports public services.

\section{Conclusions}

This article has analyzed the evolutionary process of the urban and rural sports public services. The research indicates that the urban and rural sports public services have undergone different steps from urban prior development, coordinated development of both urban and rural sports and the integrated development. It is proposed that the integrated development is an inevitable trend of the country's economic and social development. The integration of urban and rural sports public service policies is a crucial factor to ensure the integrated development of urban and rural sports public services. Therefore, the governments of all levels should strengthen the formulation, enforcement and monitoring of the policies and systems in order to promote the integrated development of urban and rural sports public service and improve the national physical quality.

\section{Acknowledgements}

This work was financially supported by the Anhui provine philosophy and Social Science Planning Project(AHSK-0910D155)

\section{References}

[1] Tian Yupu. Sports Science, Vol. 29 (2009), p. 5

[2] Fan Jida, in: Equilibrium of Basic Public Services in Urban and Rural Areas (China Finance and Economy Press, Beijing, 2008:306)

[3] Xiao Muwen. Sports Science, Vol. 29 (2009), p. 90

[4] Opinions of further Strengthening and Improving Sports Work Formulated by the Central Committee of the Communist Party and the State Council [Z]. 2002

[5] Ma Xuanjian. Journal of Chengdu Sports College, Vol. 3 (2005), p. 5

[6] Chen Zhenming, in: Politic Science(China Renming University Press, Beijing,2003:207-212)

[7] Cheng Yangguo, Administrative Tribune, Vol. 29 (2006), p. 52 